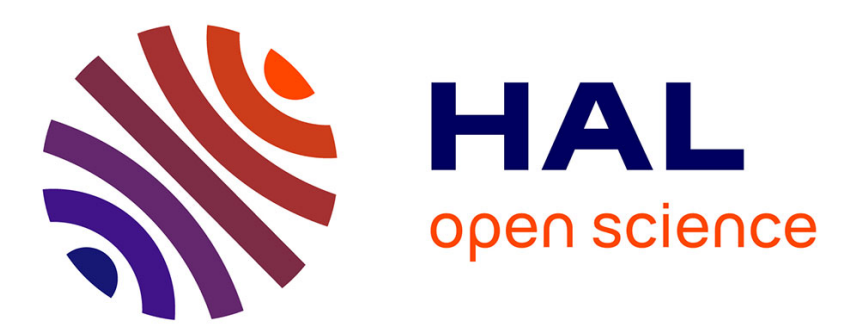

\title{
Reports of Wins and Risk Taking: An Investigation of the Mediating Effect of the Illusion of Control.
}

Frederic Martinez, Valérie Le Floch, Bernard Gaffié, Gaëlle Villejoubert

\section{To cite this version:}

Frederic Martinez, Valérie Le Floch, Bernard Gaffié, Gaëlle Villejoubert. Reports of Wins and Risk Taking: An Investigation of the Mediating Effect of the Illusion of Control.. Journal of Gambling Studies, 2011, 27 (2), pp.271-285. 10.1007/s10899-010-9204-2 . halshs-00516604

\section{HAL Id: halshs-00516604 https://shs.hal.science/halshs-00516604}

Submitted on 10 Sep 2010

HAL is a multi-disciplinary open access archive for the deposit and dissemination of scientific research documents, whether they are published or not. The documents may come from teaching and research institutions in France or abroad, or from public or private research centers.
L'archive ouverte pluridisciplinaire HAL, est destinée au dépôt et à la diffusion de documents scientifiques de niveau recherche, publiés ou non, émanant des établissements d'enseignement et de recherche français ou étrangers, des laboratoires publics ou privés. 


\begin{abstract}
Two experiments examined the relationships between the knowledge that another person has won in a gamble, the illusion of control and risk taking. Participants played a computer-simulated French roulette game individually. Before playing, some participants learnt that another person won a large amount of money. Results from a first experiment $(n=24)$ validated a causal model where the knowledge of another person's win increased the illusion of control, measured with betting times, expectancy and selfreports on scales, which in turn encourages risk taking. In the second experiment ( $n=36)$, some participants were told the previous player acknowledged the win to be fortuitous. The suppression of the belief that the previous winner had himself exerted control over the outcome resulted in lower rates of risk-taking behaviors. This suggests that it was not the knowledge of another person's win in itself that increased risk taking, but rather, the belief that the other person had some control over the gamble's outcome. Theoretical implications for the study of social mechanisms involved in gambling behavior are discussed.
\end{abstract}

Keywords: gambling, illusion of control, risk taking, social reference 
Reports of Wins and Risk Taking:

An Investigation of the Mediating Effect of the Illusion of Control

Imagine that two gamblers, Alice and Kelly, are playing on video lottery machines. Alice is playing on her own in a public house whereas Kelly is in a busy casino. Both have just lost their last Euro. Kelly then witnesses another gambler win with the usual eye-catching sight and sound display. Who will be more likely to gamble again, Alice or Kelly? To answer this question from a traditional perspective on gambling behavior, one would seek to ascertain who among the two protagonists has the longest history of gambling, what social norms govern public house gambling behavior, or what are their individual differences (e.g., family history, intelligence, extraversion, substance abuse, etc.). In the present study, however, we address this issue from the perspective of social cognition. As suggested by Rockloff and Dyer (2007), co-actors or an audience may facilitate performance for a variety of behaviors. Building upon this observation, this study aims to gain a better understanding of the effect of knowing that someone else has won on one's own gambling behavior.

Stories about gambling wins are widely publicized by the media yet losses are much more frequent than wins (Hill \& Williamson, 1998; McMullan \& Mullen, 2001). These practices may have important consequences on gambling behavior. For instance, knowing that someone else has won has been shown to increase individuals' risk taking (Kearnay \& Drabman, 1992; Le Floch, Martinez,\& Gaffié, 2004). However, little is known about the mechanisms that underpin the effect of reports of wins on gambling behavior. There is evidence showing that the perception of other gamblers' characteristics can influence an individual's illusion of control (Dykstra \& Dollinger, 1990; Langer, 1975) and this illusion has been suggested to be a key factor in increasing risk taking (e.g., Walker, 1992). This suggests a causal model within which the illusion 
of control could be a mediator of the effect of the knowledge of another person's win on one's risk-taking behavior (see Figure 1). In the next section, we critically review evidence from the literature supporting this model. We then present two experiments that provide a direct empirical test of this model. In the first experiment, we sought to discover if reports of wins increased beliefs in the winner's ability to control the outcome of the gamble. In the second experiment we sought to test whether the suppression of the belief that the previous winner had exerted control over the gamble's outcome could cancel the effect of reports of wins on risk taking.

\section{Linking Reports of Wins, Risk taking and the Illusion of Control}

\section{Why and how reports of wins increase gambling behaviors and risk taking?}

Studies anchored in social learning theory (Bandura, 1977) have shown that peer modeling frequently induced risk-taking behavior in children and adolescents (Browne \& Brown, 1994, Hardoon \& Derevensky, 2001). For example, preschool children were shown to be more likely to engage in risk-taking behavior in a game of pure chance after seeing a peer having just ostensibly won this game (Kearney \& Drabman, 1992).With adults, witnessing the win seems unnecessary to increase risk taking. Mushquash (2004) indeed reported that about half of 182 respondents from the general public felt the urge to gamble after learning that someone else had won. A recent study (Rockloff \& Dyer, 2007) investigated the existence of a social facilitation effect (Zajonc, 1965) for gambling behavior on electronic gaming machines. Some participants received false feedback from the computer designed to suggest that other gamers in adjacent rooms were playing and sometimes winning at the same game. This experiment demonstrated that the implied presence and wins of other gamblers intensified gambling, measured by greater persistence and lower final payouts. 
Martinez, Le Floch, and Gaffié (2005) directly tested whether reporting another person's win would affect subsequent gambling behavior under laboratory conditions. This study did not test the effects of the presence of co-actors on gambling behavior in real time. However, it suggested that information about the performance of others is likely to intensify gambling behavior as measured by risk taking. In this study, participants individually played a computer-simulated "French roulette game"1 and were falsely told that a previous participant had a large or a small win during their play. Results indicated that the knowledge alone of another person's large win was enough to increase risk taking. In the following section, we begin by reviewing evidence suggesting that reports of others' wins may indeed lead to an increase in illusion of control.

\section{Why and how reports of wins lead to an increase in illusion of control?} Langer (1975) defined the illusion of control as the "expectancy of a personal success probability inappropriately higher than the objective probability would warrant." (p. 313). According to Langer, the more skill-related factors (choice, stimulus familiarity, active involvement, and competition) are present in a game of chance, the more an illusion of control is likely to occur. In her first study, Langer (1975) examined the effect of competition in a game of pure chance where the player selecting the highest card would win the betting round. She demonstrated that participants bet significantly more money when playing against an incompetent competitor than when playing against a competent one. Langer interpreted these results as showing that, in direct competition, participants disregard the uncontrollable and random nature of chance. Instead they misconceive the game of pure chance as a skilled task where their

\footnotetext{
${ }^{1}$ There are several variants of the «roulette» game; the French roulette is the most popular version in European casinos in general, and in French casinos, in particular.
} 
probability of winning depend on their level of competence relative to that of other players and where they can apply strategies to increase their wins.

Direct competition, however, is not necessary to generate such an illusion of control. Dykstra and Dollinger (1990) did not use a directly competitive task: they merely showed to their participants a video of another player that was either presented as a competent gambler or as an incompetent one. Results showed that participants who had watched an incompetent-looking model gave higher estimates of their own success at the game. These results suggest that participants evaluate how well they could perform in the chance task based on their perception of the other gambler's competence as if it were a skilled task.

Martinez et al. (2005) reported that the knowledge of another person's win significantly increased the time taken by participants to select bets. General decisions result from a compromise between the desire to make a correct choice and the desire to minimize effort (Lipman, 1991; see also Payne, Bettman \&Johnson, 1993). Additionally, the amount of effort spent on a task is regulated as a function of the expected effects of the actions undertaken (Bandura, 1986). Thus, one may expect that individuals will only "invest" in making the effort of thinking when they perceive the task to be controllable. In fact research has already established that individuals who believe they have little control over subsequent outcomes do not persevere as much as those who believe they can exert control over these outcomes (Testa \& Major, 1990). Thus the longer time taken to place bets under the knowledge of another gambler's win in Martinez et al.'s (2005) study could be interpreted as additional, albeit indirect, evidence for the hypothesis that knowledge of another gambler's win entails an increase in illusion of control. 
On the basis of these results, we expect that knowing how much another gambler has won will be interpreted as a skill-related cue. Specifically, reports of wins should increase the belief that gambling is a skilled task and thereby induce an illusion of control, which in turn would lead to an unrealistic anticipation of personal success. To validate our proposed causal model (see Figure 1), the link between illusion of control and risk taking should also be established. We review evidence for such a link in the following section.

\section{Do we take more risks when we believe we can control the outcome of a}

\section{situation?}

The illusion of control has often been suggested to be a key factor in increasing risk taking (Dixon, 2000; Griffiths, 1994; Ladouceur \& Walker, 1996; Langer, 1975; Walker, 1992). Although illusory control does appear to encourage risk-taking in other domains (Horswill \& McKenna, 1999), the link between taking risks and overlooking the uncontrollable and random nature of chance has not been firmly established in gambling games. Delfabbro and Winefield (2000) found that players who staked more money also verbalized more thoughts, which in turn would suggest they erroneously assessed their ability to control the game. However, the authors themselves acknowledged that participants' spontaneous verbalizations may represent a post facto justification for their risk-taking behavior rather than a causal determinant of such behavior. Similarly, Caron and Ladouceur (2003) showed that participants exposed to an accomplice's deceptive verbalizations (e.g., "now, I played really badly!") took more risks than participants who heard adequate verbalizations (e.g., "it's too bad that we don't control chance!") or no verbalization at all. The authors, however, did not measure the effect of the accomplice's verbalizations on participants' own beliefs. 
Therefore, a direct causal link between erroneous beliefs on controllability and risktaking behaviors remains to be empirically established.

\section{The Present Study}

The present study aimed to test a causal model where the illusion of control is a mediator of the effect of reports of others' wins on one's risk-taking behavior (see Figure 1). In order to test this model, we first manipulated whether or not gamblers knew about another person's win and assessed the effect of this manipulation on gamblers' illusion of control and risk-taking behavior. In addition, to test for the hypothesis that the illusion of control was a mediator of the causal relation between knowledge of another's win and risk taking, we also directly assessed whether the degree of illusory control affected risk taking.

Thus, building on Martinez et al.'s (2005) findings, we expected that knowing how much a previous player had won in a gamble would increase risk taking. Specifically, we anticipated that the knowledge of another person's win would strengthen the belief that Roulette is a game of skill, which requires strategic, effortful thinking. Consequently, knowledge of another person's win was expected to result in increased gains expectancy and increased betting times. Finally, we hypothesized that an increase in the illusion of control would also lead to an increase in risk taking. We report two experiments. The first experiment examined whether the illusion of control is a mediator of the effect of knowing another gambler's win on risk-taking. The second experiment examined whether discrediting the belief that the other gambler may have won by exerting control over the gamble's outcome is sufficient to eliminate the effect of knowing about this gambler's wins. 


\section{Experiment 1}

\section{Method}

\section{Participants}

An opportunity sample of 24 female students was selected in the Psychology building of the University of Toulouse. Ages ranged from 18 to 27 years. None of the participants in either this or the following experiment had any history of gambling, nor were they familiar with French roulette.

Design

Participants were randomly assigned to one of two groups (equal number per cell).In the experimental group, participants were informed of the amount won by the previous gambler. In the control group, this information was omitted. Each participant took part in 15 game trials ${ }^{2}$.

The illusion of control, the hypothesized mediating psychological construct (see Figure 1), was measured with three dependent variables. From a statistical point of view, mediators are defined as variables that "transmit the effect of one variable to another variable" (MacKinnon, Fairchild, \& Fritz, 2007, p. 594) whereby a cause only indirectly affect an outcome through a mediator. The construct validity of the variable conceptualized as the statistical mediator is an important concern in testing mediation. To remove the biasing effect of measurement error, Baron and Kenny (1986) advised that multiple independent and converging measurements should be collected to tap a latent variable. Therefore, we used two classical subjective measurements of illusion of control (Langer, 1975): the belief that gambling is a skilled task (assessed with selfreport scales) and their gain expectancy (measured as the expected number of chips at the end of the gambling session). Additionally, akin to Martinez et al. (2005), we

\footnotetext{
${ }^{2}$ Note that although the number of participants per cell was relatively small, each of these participants participated in fifteen trials (see procedure) thereby increasing the power to detect treatment effects.
} 
measured the time taken to place bets as a potential additional measurement of illusion of control.

Finally, risk taking, the outcome variable, was measured using the RT index (Martinez et al., 2005; see Appendix 2) adapted from Ladouceur and Mayrand (1986) which takes into account the number of chips placed on a bet as well as the probability of losing one's stakes, and the current resources of the gambler at the time of betting.

\section{Materials and Procedure}

Participants were invited to play a computer-simulated French roulette game individually for 45 minutes. In fact, the experiment stopped at the $15^{\text {th }}$ round and lasted around 25 minutes. This was to ensure that participants would not suspect that the experiment was to stop when it did and as a result would not be tempted to place all their chips on the last bet. The experimenter explained the rules of the French roulette to the participants (See Appendix 1).

The different types of bets possible, their placement on the layout table (reproduced in Figure 2), the probability of a win and their potential payouts (summarized in Table 1) were then presented to the participants. A booklet summarizing this information was available throughout the course of the experiment. Following this presentation, the experimenter explained the functioning of the software. Participants were given a credit of a 100 chips. At any point in the game, they were able to see the number of chips they had left on the computer screen. They were warned that the program would stop automatically if they lost all their chips. For each game trial, the software recorded the number chips placed on any given bet, the probability of losing this bet, and the current resources of the gambler at the time of placing the bet(s). These measures were later used to calculate the risk taking index. 
In addition, participants in the experimental condition were given the following information before the start of the game (translated from the French):

"At the end of the game, I will write down the number of chips you have left on the sheet under the keyboard. As you can see on this sheet, Dominique Fabre ${ }^{3}$ who played before you has won 750 chips." To avoid raising the suspicions of participants, the experimenter then drew their attention to the disorderly state of the room and said: "Why is there a sheet of paper under the keyboard? I'll remove it later". The reminder of another person's win thus remained visible throughout the duration of the experiment. In the control group, the experimenter indicated a blank sheet and simply said: "At the end of the game, I will write down the number of chips you have left on the sheet under the keyboard."

Participants completed their familiarization with the task with five practice trials ${ }^{4}$. Before the game session began, participants were asked to report how many chips they expected to have at the end of the game (expectancy measure) as well as to rate their agreement with two statements ("There are strategies that increase the probability of winning"; "The more I think about strategies to place my bets, the more I increase my probability of success") on a 7-point scale from "totally disagree" to "totally agree" (subjective illusion of control measure). In addition, the time they took to place a bet was recorded on each betting trial.

\footnotetext{
${ }^{3}$ This name was selected because it is gender neutral in French.

${ }^{4}$ Since participants were not familiar with the Roulette game, the experimenter enquired several times about the participants' understanding of the rules of this game and offered to re-explain the rules. All participants confirmed they had understood the rules. This was also confirmed by their gambling behaviours which were also suggestive of a good understanding of the game rules.
} 


\section{Results and Discussion}

\section{Does knowing about another gambler's win affects risk taking and illusion of control?}

Participants' risk taking (RT) on each given trial was calculated by taking into account the number of chips placed on any given bet, the objective probability of winning with such a bet as well as the total number of chips owned by the gambler at the time of placing the bet(s) (see Appendix 2 for the exact formula). The resulting score was greater than 0 and less than 1 where a higher score was indicative of greater risk taking. Those RT scores were averaged across the fifteen trials to provide one risktaking index per participant. Overall, participants' RT index was higher when they knew the previous gambler had won 750 chips; $M=.12(S D=.08)$ vs. $M=.03(S D=$ .01) in the control group. A one-way analysis of variance (ANOVA) confirmed this difference was statistically significant; $F(1,22)=13.62, p<.001$ partial $\eta^{2}=.38$.

Ratings for the two statements about personal control were significantly and highly correlated; $r(24)=.84, p<.001$; and were averaged to form an index of subjective personal control. Participants' index of personal control was again higher when they knew the previous gambler had won 750 chips; $M=5.92(S D=.79)$ vs. $M=$ $3.17(S D=1.47)$ in the control group. This difference was reliable; $F(1,22)=32.64, p$ $<.001$, partial $\eta^{2}=.59$. Finally, learning about someone else's win also resulted in greater gain expectancies; $M=235(S D=134.06)$ vs. $M=61.75(S D=57.96)$ in the control group; and longer times to place a bet; $M=31.62 \mathrm{~s}(S D=7.19) \mathrm{vs.} M=19.67 \mathrm{~s}$ $(S D=5.89)$ in the control group. Once again, both these differences were statistically reliable; $F(1,22)=16.89, p<.001$ partial $\eta^{2}=.43$ and $F(1,22)=19.83, p<.001$, $\operatorname{partial} \eta^{2}=.47$ respectively. 


\section{Does illusion of control mediates the effect of knowing about another gambler's win on risk taking?}

Although the results presented above are consistent with our hypotheses, they do not, in themselves, attest to the mediating effect of the illusion of control. To test for our causal model, we followed Baron and Kenny's (1986) regression-based procedure to test for mediation effects. In line with Martinez et al.'s (2005) findings, the longer the betting times the greater the score on self-report measures of the illusion of control, $r$ $(24)=.72, p<.001$, and the greater the number of chips the participants expected to retain at the end of the game; $r(24)=.70, p<.001$. We therefore standardized these three variables and computed an average score, which provided an estimate of the latent illusion of control construct for each participant.

Regression analyses showed that knowledge of another person's win was a significant predictor of risk-taking index, $\beta=.62, t(24)=3.69, p<.01$, and a significant predictor of illusion of control, $\beta=.82, t(24)=6.74, p<.001$. However, when the risktaking index was regressed on both knowledge of another person's win and illusion of control, the effect of knowledge of another's win became non-significant, $\beta=.15, t(24)$ $=.54, p=.59$, while the illusion of control remained a significant predictor of risktaking, $\beta=.57, t(24)=2.11, p<.05$ (adjusted $R^{2}=.44$ for the full model). A Sobel test confirmed that the effect of this mediation was significant $(z=1.98, p<.05)$.

Altogether, these results, summarized in Figure 3, establish what Baron and Kenny refer to as a "perfect mediation".

The purpose of this first experiment was to test a causal model of risk-taking behavior in gambling. The present results confirmed that the effect on risk taking of knowing about previous players' wins was mediated by players' increased illusion of control. As such, these results suggest that, in the absence of any other information, the 
previous gambler's win was misinterpreted as a sign that this previous player was skilful, rather than merely lucky. Previous research has established that the perceived level of competence of other gamblers may affect one's own illusion of control (e.g., Dykstra \& Dollinger, 1990). It is thus plausible to assume that the misattribution of the previous gambler's win to their skill amplified participants' illusion of control, which, in turn, resulted in an increase in risk taking. Experiment 2 was designed to provide an empirical test for this explanation.

\section{Experiment 2}

The second experiment aimed to further examine what motivated participants' increase in illusory control upon learning the (successful) outcome of a previous player. We hypothesized that this resulted from the misattribution of the previous' player outcome to their skilfulness. If this explanation is correct, the extent of gamblers' illusion of control and as well as the extent to which they place risky bets should be positively correlated with the degree of personal control they attribute to the previous gambler. Furthermore, players should no longer be influenced by the knowledge of the previous gambler's win if they are made aware that this win was fortuitous. Such information should prevent the misinterpretation of the previous gambler's win as evidence of their skillfulness. Thus, we anticipated that knowing that a previous player had fortuitously won should have no effect on participants' perceived personal control and hence, no longer affect their risk taking. We tested these predictions in Experiment 2. 


\section{Method}

\section{Participants}

An opportunity sample of 36 female students was selected in the Psychology building of the University of Toulouse. Ages ranged from 19 to 26 years. None of these students had been participants in Experiment 1.

\section{Design}

Participants were randomly assigned to one of three groups. The first experimental condition (hereafter the "win" condition) and the control condition were identical to the conditions used in Experiment 1. In a second experimental condition, (hereafter the "fortuitous win" condition), participants also learnt that a previous gambler had won a large amount; however, they were also informed that this win had been acknowledged as fortuitous. The dependent measures were identical to those used in Experiment 1. In addition, at the end of the experiment, all participants were asked to rate the extent to which the previous gambler controlled the situation on a scale ranging from 0 (not at all) to 20 (completely).

\section{Materials and Procedure}

The materials and procedure were identical to those used in Experiment 1. Participants in the "win" and in the "fortuitous win" condition learnt that the previous player had won 750 chips. In the fortuitous win condition, however, the experimenter added: "but she told me that she did not control the situation. She played randomly and unexpectedly won 750 chips".

\section{Results and Discussion}

As expected, gamblers' illusion of control and risk taking was related to the degree of control they attributed to the previous winner. A significant positive correlation was observed between the degree of control attributed to the previous 
winner and participants' subjective estimates of personal control, $r(24)=.72, p<.001$, their gain expectancy, $r(24)=.46 p<.05$, and their betting times, $r(24)=.43, p<.05$. Attributed control also was also strongly correlated with participants' own risk taking index, $r(24)=.59, p<.001$.

As predicted, risk-taking indices were affected by the way in which the wins of the previous player were specified; $F(2,33)=10.5, p<.001, \eta^{2}=.39$. Participants who were simply told that the previous player had won 750 chips took higher risks when betting compared to those had no information, $M=.09(S D=.04)$ vs. $M=.03(S D=$ .03). Planned comparisons revealed that this difference was reliable, thus replicating our findings from Experiment 1, Dunnett's $F(1,22)=13.62, p<.01$. By contrast, participants who were told that the previous gambler's win was fortuitous exhibited similar levels of risk taking than those in the control condition, $M=.03(S D=.03)$ vs. $M=.03(S D=.03)$, Dunnett's $F(1,22)=.01, p=.63$.

A similar pattern of results was observed for the measures of illusory control. All measures were affected by the type of report of wins, $F(2,33)=5.7, p<.0, \eta^{2}=.26$, $F(2,33)=4.64, p<.05, \eta^{2}=.22$, and $F(2,33)=11.66, p<.001, \eta^{2}=.41$ for the subjective estimates of personal control, expectancy, and betting times, respectively. Planned contrasts revealed that being told that the previous gambler won 750 chips increased participants' perceived personal control, $M=5.33(S D=1.45)$ vs. $M=3.63$ $(S D=1.33)$ in the control condition, Dunnett's $F(1,22)=9.02, p<.01$. It also significantly increased expectancy, $M=195.67(S D=191.61)$ vs. $M=65.92(S D=$ 47.74) in the control condition, Dunnett's $F(1,22)=5.18, p<.05$. Finally, it also significantly increased betting times, $M=41.91(S D=8.46)$ vs. $M=19.8(S D=5.9)$, Dunnett's $F(1,22)=12.92, p<.01$. These results therefore replicated Experiment 1 's findings. 
In keeping with our current predictions, however, participants in the "fortuitous win" condition behaved no differently from those in the control group. They exhibited the same level of personal control: $M=3.83(S D=1.27)$ vs. $M=3.63(S D=1.33)$, Dunnett's $F(1,22)=.16, p=.91$; provided similar expectancy estimates, $M=74.58(S D$ $=42.39)$ vs. $M=65.92(S D=47.74$, Dunnett's $F(1,22)=.22, p=.98$ and took similar amounts of time to place their bets, $M=20.75(S D=5.34)$ vs. $M=19.8(S D=5.9)$, Dunnett's $F(1,22)=.17, p=.59$.

Finally, we sought to replicate the analysis for mediation effect of illusion of control when participants were simply told another player had won 750 chips compared to the control group. Results showed all criteria for mediation were satisfied. Specifically, knowledge of the previous player's win was a significant predictor of risktaking, $\beta=.62, t(24)=3.68, p<.01$, and a significant predictor of the illusion of control, $\beta=.6, t(24)=3.51, p<.01$. When, however, the risk-taking index was regressed on both knowledge and illusion of control, the latter remained a significant predictor, $\beta=.63, t(24)=3.82, p<.01$ while the effect of the knowledge of another person's win on the same index was no longer a significant predictor, $\beta=.24, t(24)=$ $1.47, p=.16$, (adjusted $R^{2}=.61$ for the full model). These analyses thus replicated the "perfect mediation" (Baron \& Kenny, 1986) observed in Experiment 1, Sobel test $z=$ $2.53, p<.05$. Figure 4 summarizes these results.

To summarize, this second experiment demonstrated that the increase in risk taking subsequent to the report of a previous player's win was contingent on the belief that this player had exerted control over the outcome of his game session. The degree of control assigned to another person was strongly and positively correlated with participants' own illusion of control and risk taking. When participants believed that the previous winner had no control over the outcome of his gamble, learning the amount he 
had won no longer affected participants' illusory control or risk taking. When, however, participants were simply told about the amount won by the previous player, such knowledge significantly increased their risk taking, and their level of illusion of control was a significant mediator of this relationship, thereby replicating the results obtained in Experiment 1.

\section{General discussion}

The literature on the psychology of gambling suggests that gambling behavior can be facilitated by several determining factors, such as the physiological arousal that occurs when an individual is in a casino (Anderson \& Brown, 1984; Dickerson, Hinchy, England, Fabre \& Cunningham, 1992), the presence of other gamblers who recognize gambling as socially acceptable (Wood \& Griffiths, 1998), the imitation of other gamblers (Gupta\& Derevensky1997; Hardoon \& Derevensky, 2001), or the transmission of erroneous verbal information about the concept of chance (Caron \& Ladouceur, 2003). All these accounts suggest that Kelly, the fictitious character introduced earlier, would be more likely to gamble again because she is playing in a casino, among other gamblers, rather than on her own in a public house. Kelly would also witness other players gambling and, sometimes, winning.

Our objective in this article was to test an alternative explanatory model of the urge to gamble where knowing that another gambler has won increases illusion of control, which in turn encourages risk taking. Martinez et al. (2005) found that betting times was a significant mediator of the effect of reports of wins on risk taking. Increased betting times under the knowledge of another player's outcome, however, could have been a reflection of many other concerns such as distractibility or peerpressure. The present study used multiple independent and converging measures of the mediator to improve the illusory control construct validity. As such it extended 
Martinez et al. (2005) work by using a sounder methodology to assess the mediating effect of illusory control.

Moreover, this study provided the first demonstration that when the win of the previous gambler was reported to be fortuitous, it not longer affected players' own illusion of control or risk-taking behaviors (Experiment 2). This finding confirms that it is not the knowledge of another person's win in itself that increases one's risk taking, but rather the belief that this win came about because the other player was able to exert control over the outcome of the gamble. Together, these findings clearly reveal how social influences such as reports of another player's win may affect gambling behavior.

\section{Limitations and Future Research}

Participants in this study knew they would not lose any real money, possibly limiting the generalizability of our findings. Although Kühberger, Schulte-Mecklenbeck and Perner (2002) found that "hypothetical" decisions (without real payoffs) appeared to match "real" decisions in laboratory tasks. They also added that this may not hold true for decisions where emotions and motivated needs play an important role, as it would be difficult to elicit these emotional states with hypothetical decisions. Given that real gambling decisions give rise to higher emotions than artificial ones (Anderson \& Brown, 1984), the behaviors of the participants may have differed from those observed in real casinos. Anecdotal evidence suggests that our participants were indeed emotionally involved in the computer-based lottery game, as they tended to express great pleasure upon winning and great dissatisfaction upon losing. More importantly, higher levels of emotional involvement should be unlikely to favor rational thinking and if anything should lead to an increase in the illusion of control. As such, we would expect those results are likely to hold outside the laboratory. 
The fact that only one type of game (French roulette) was used could be seen as another limitation of this research. Indeed, the numerous types of possible bets at each round may have given participants the impression that their probability of winning could be increased through the use of strategies. The mere act of choosing a lottery ticket has been shown to inflate perceptions of winning odds (Langer, 1975; Wohl \& Enzlze, 2002). In addition, Gilovich and Douglas (1986) found that subjects who personally made a series of choices exhibited a bias in their outcome evaluations. However, Wohl and Enzle (2002) found that the mediating variable for such biases is not the belief in one's ability to select the "winning ticket", but rather the belief that luck is a personal quality that can be used intentionally. In our study, however, participants selecting bets in the "fortuitous win" condition (Experiment 2) did not show any increase in illusion of control. This result demonstrates that the key determinant in generating an increase in illusion of control is the belief that the previous winner controlled the gamble rather the mere opportunity to choose among different bets.

Finally, an interesting direction for future research would be to investigate individual characteristics, which may affect players' sensitivity to the report of other's wins. Abrams and Kushner (2004), for example, emphasized the importance of dispositional traits (e.g., impulsiveness, sensation seeking and extraversion) in the development of pathological gambling. Similarly, individuals with varying scores on the PGS index (Problem Gambling Severity index, Ferris \& Wynne, 2001) may be more or less sensitive to the report of others' wins.

\section{Conclusions}

Our results illustrated the importance of studying social factors in understanding gambling behaviors. We were able to demonstrate that the knowledge of the amount won by another gambler increased the new player's illusion of control over the outcome 
of the gamble, which in turn increased the risks this player was willing to take, unless the reported win was qualified as fortuitous. The present findings have potentially important implications for the study of risky decision making in general. For example, a well-known consequence of Prospect theory (Kahneman \& Tversky, 1979; Tversky \& Kahneman, 1992) is that individuals tend to be risk averse in the domain of wins: they would rather choose to win $\$ 3,000$ for sure than take part in a gamble for an $80 \%$ chance of winning $\$ 4,000$. Our findings suggest, however, that this classic pattern of choice could be inverted simply by letting the decision-maker know that another person who chose to gamble has won $\$ 4,000$. Finally, those results also have important implications for the prevention of excessive gambling behaviors: they suggest that an efficient measure to inhibit the effect of others' wins on one's own gambling in games of pure chance such as the French roulette could be to remind players that those wins are fortuitous. 


\section{References}

Abrams, K., Kushner, M. G.(2004). Behavioral Understanding in Pathological gambling: A clinical guide to treatment. Grant, Jon E. (Ed.); Potenza, Marc N. (Ed.); Arlington, VA, US: American Psychiatric Publishing, Inc., 2004. pp. 113126

Anderson, G., \& Brown, R. I. F. (1984). Real and laboratory gambling, sensationseeking and arousal. British Journal of Psychology, 75, 401-410.

Bandura, A. (1977). Social learning theory. Englewood Cliffs, NJ: Prentice-Hall.

Bandura, A. (1986). Social foundations of thought and action: A social cognitive. Englewood Cliffs, NJ: Prentice Hall.

Baron, R. M., \& Kenny, D. A. (1986). The moderator-mediator variable distinction in social psychological research: Conceptual, strategic, and statistical considerations. Journal of Personality and Social Psychology, 51, 1173-1182.

Browne, B. A., \& Brown, D. J. (1994). Predictors of lottery gambling among American college students. Journal of Social Psychology, 134, 339-347.

Caron, A., \& Ladouceur, R. (2003). Erroneous verbalizations and risk taking at video lotteries. British Journal of Psychology, 94, 189-194.

Dickerson, M., Hinchy, J., Legg England, S., Fabre, J., \& Cunningham, R. (1992). On the determinants of persistent gambling behaviour. High-frequency poker machine players. British Journal of Psychology, 83, 237-248.

Delfabro, P. H., \& Winefield, A. H. (2000). Predictors of irrational thinking in regular slot machine gamblers. The Journal of Psychology, 134, 117-128.

Dixon, M. R. (2000). Manipulating the illusion of control: Variations in gambling as a function of perceived control over chances outcomes. The Psychological Record, 50, 705-719. 
Dykstra, S. P., \& Dollinger, S. J. (1990). Model competence, depression, and the illusion of control. Bulletin of the Psychonomic Society, 28, 235-238.

Ferris, J., \& Wynne, H. (2001). The Canadian problem gambling index: Final report: Canadian.Centre on Substance Abuse.

Gilovich, T., \& Douglas, C. (1986). Biased evaluations of randomly determined gambling outcomes. Journal of Experimental Social Psychology, 22, 228-241.

Griffiths, M. D. (1994). The role of cognitive bias and skill in fruit machine gambling. British Journal of Psychology, 85, 351-369.

Gupta, R., Derevensky, J.L. (1997). Familial and social influences on juvenile gambling behavior. Journal of Gambling Studies, 13, 179-192.

Hardoon, K. K., \& Derevensky, J. L. (2001). Social influences in children's gambling behavior. Journal of Gambling Studies, 17, 191-214.

Hill, E., \& Williamson, J. (1998). Choose six numbers, any numbers. The Psychologist, $11,17-21$.

Horswill, M. S.,\& McKenna, F. P. (1999). The effect of perceived control on risk taking. Journal of Applied Social Psychology, 29, 378-392.

Kahneman, D., \& Tversky, A. (1979). Prospect theory: An analysis of decision under risk. Econometrica, 47, 263-291.

Kearney, C. A., \& Drabman, R. S. (1992). Risk Taking/Gambling-like behavior in preschool children. Journal of Gambling Studies, 8, 287-297.

Kühberger, A., Schulte-Mecklenbeck, M., \& Perner, J. (2002). Framing decisions: Hypothetical and real. Organizational Behavior and Human Decision Processes, $89,1162-1175$. 
Ladouceur, R., \& Mayrand, M. (1986). Caractéritiques psychologiques de la prise de risque monétaire des joueurs et des non-joueurs à la roulette. International Journal of Psychology, 21, 433-443.

Ladouceur, R., \& Walker, M. (1996). A cognitive perspective on gambling. In P. M. Salkovskis (Ed.), Trends in cognitive therapy (pp. 89-120). Oxford: Wiley.

Langer, E. J. (1975). The illusion of control. Journal of Personality and Social Psychology, 32, 311-328.

Le Floch, V., Martinez, F., \& Gaffié, B. (2004). L'annonce du résultat d'autrui : un second point de référence? Canadian Journal of Behavioural Science, 36(4), 310-320.

Lipman, B. (1991). How to Decide How to Decide How to ...: Modeling Limited Rationality, Econometrica, 59(4), 1105-1125.

MacKinnon, D. P., Fairchild, A. J., \& Fritz, M. S. (2007). Mediation analysis. Annual Review of Psychology, 58, 593-614.

Martinez, F., Le Floch, V., \& Gaffié, B. (2005). Lien entre perception de contrôle et prise de risque dans un jeu de hasard: Quand l'annonce d'un gain d'autrui intervient. Revue Internationale de Psychologie Sociale, 18 (3),129-151.

McMullan, J. J., \& Mullen, J. (2001). What makes gambling news? Journal of Gambling Studies, 17, 321-352.

Mushquash, C. (2004). An examination of the cue-reactivity of Gambling wins. MA Thesis: Department of Psychology, Lakehead University.

Payne, J.W., Bettman, J.R., \& Johnson, E.J. (1993). The adaptative decision maker. New York: Cambridge University Press.

Rockloff, M., \& Dyer, V. (2007). An experiment on the social facilitation of gambling behavior. Journal of Gambling Studies, 23, 1-12. 
Testa, M., \& Major, B. (1990). The impact of social comparisons after failure: The moderating effects of perceived control. Basic and Applied Social Psychology, $11,205-218$.

Tversky, A., \& Kahneman, D. (1992). Advances in propect theory. Cumulative representation of uncertainty. Journal of Risk and Uncertainty, 5, 297-323.

Walker, M. B. (1992). The psychology of gambling. Oxford: Permagon Press.

Wohl, M. J. A., \& Enzle, M. E. (2002). The deployment of personal luck: Sympathetic magic and illusory control in games of pure chance. Personality and Social Psychology Bulletin, 28, 1388-1397.

Wood, R. T., \& Griffiths, M. D. (1998). The acquisition, development and maintenance of lottery and scratchcard gambling in adolescence. Journal of Adolescence, 21, 265-273.

Zajonc, R. B. (1965). Social Facilitation. Science, 149 (3681), 269-274. 
Appendix 1: The rules of French roulette

"French roulette is a game of pure chance based on the random selection of a number between 0 and 36 inclusive. The roulette wheel is divided into 37 evenly spaced slots numbered 0 , and 1 through 36 . The zero slot is green and the other numbers are either red or black. These numbers are reproduced in a grid on the layout table (displayed on the computer screen). Several other boxes are represented outside this grid of numbers. Before the wheel is spun, players make bets against the House by placing chips in various boxes or on the lines between the boxes on the layout table. A small ivory ball is then released into the outer edge of the spinning wheel, circling many times before slowing down. As the ball loses momentum it falls and drops into one of the slots to end that round of the game. There are three main categories of bets, distinguished by their winning odds and payouts. All combinations of these bets are possible in the same attempt; you can win or lose in each different bet you place." 
Appendix 2: Risk taking index (Martinez et al., 2005)

$R T=\frac{\sum N C \times P L}{C T}$

$R T$ represents the amount of risk taken; $N C$, the number of chips placed on any given bet; $P L$, the probability of losing of this bet; and $C T$, the resources of the gambler at the time of placing the bet(s). The value of this measure varies in theory on a scale from 0 to 1 . In practice, it can neither be equal to 0 (since $N C>0$ and $P L>0$ ), nor 1 (since $P L<$ $1)$. 
Table 1

Chances of Winning and Payout for Each Type of Bet Allowed in the French Roulette Game

\begin{tabular}{ccc} 
Type of bet & Chances of winning & Payout \\
\hline Simple bets (7) & $18 / 37$ & $1: 1$ \\
Black & $18 / 37$ & $1: 1$ \\
Red & $18 / 37$ & $1: 1$ \\
Odd & $18 / 37$ & $1: 1$ \\
Even & $18 / 37$ & $1: 1$ \\
1 to 18 & $18 / 37$ & $1: 1$ \\
19 to 36 & &
\end{tabular}

Double bets
Columns (5)
$12 / 37$
$2: 1$
Dozens (6)
$12 / 37$
$2: 1$

Multiple bets

$\begin{array}{lcc}\text { One-number bet(1) } & 1 / 37 & 35: 1 \\ \text { Two-number bet(2) } & 2 / 37 & 17: 1 \\ \text { Three-number bet(3) } & 3 / 37 & 11: 1 \\ \text { Four-number bet(4) } & 4 / 37 & 8: 1\end{array}$

Note. The numbers in brackets refer to the key to Figure 1. 


\section{Figure captions}

Figure 1: Proposed overall model of causal relationships between the knowledge of another's win and risk taking.

Figure 2: The placement of different types of bets on the layout table

Figure 3: Causal model between the knowledge of another person's win, betting times and risk-taking behavior in Experiment 1. (The values in brackets are the standardized regression coefficients $\beta$; those without brackets are the same coefficient when the third variable is statistically controlled)

Figure 4: Causal model between the knowledge of another person's win, betting times and risk-taking behavior in Experiment 2. (The values in brackets are the standardized regression coefficients $\beta$; those without brackets are the same coefficient when the third variable is statistically controlled) 


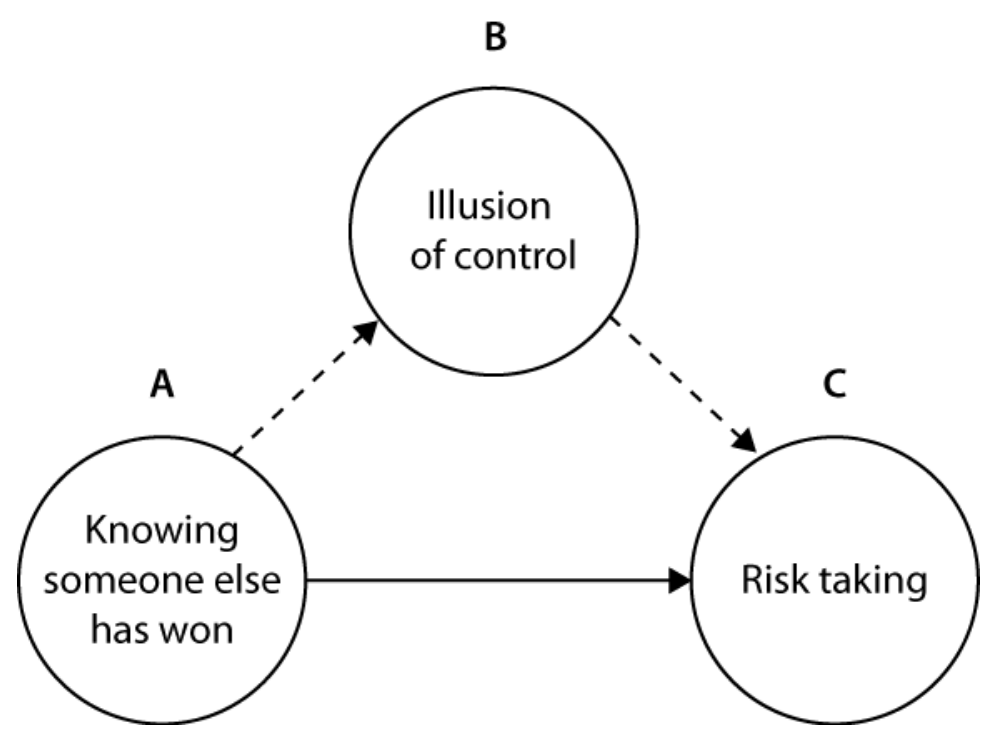




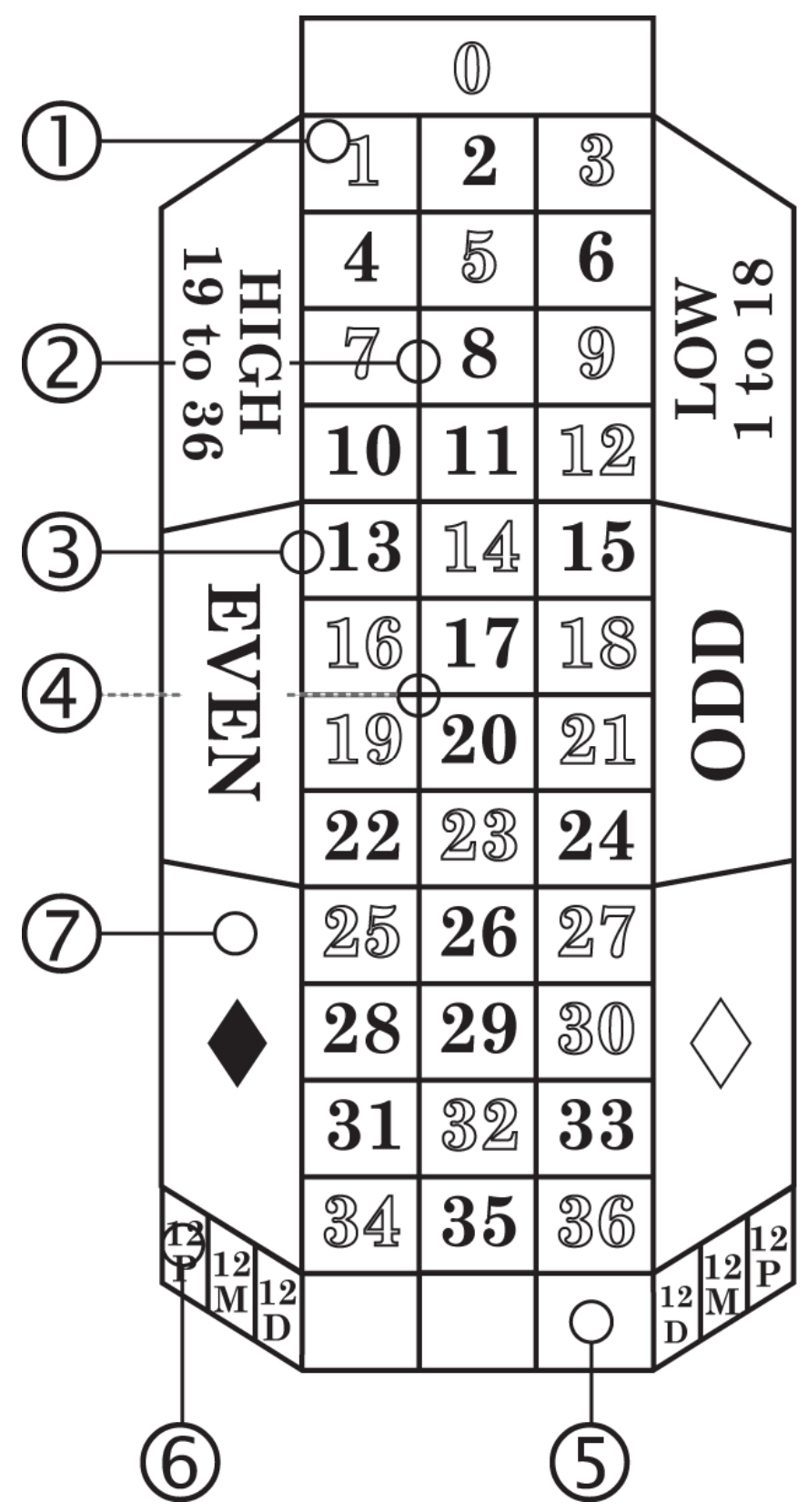

Key

(1) One-number bet

(2) Two-number bet

(3) Three-number bet

(4) Four-number bet

(5) Third column bet

6) First dozen bet

(7) Black simple bet 
Reports of Wins and Risk Taking 31

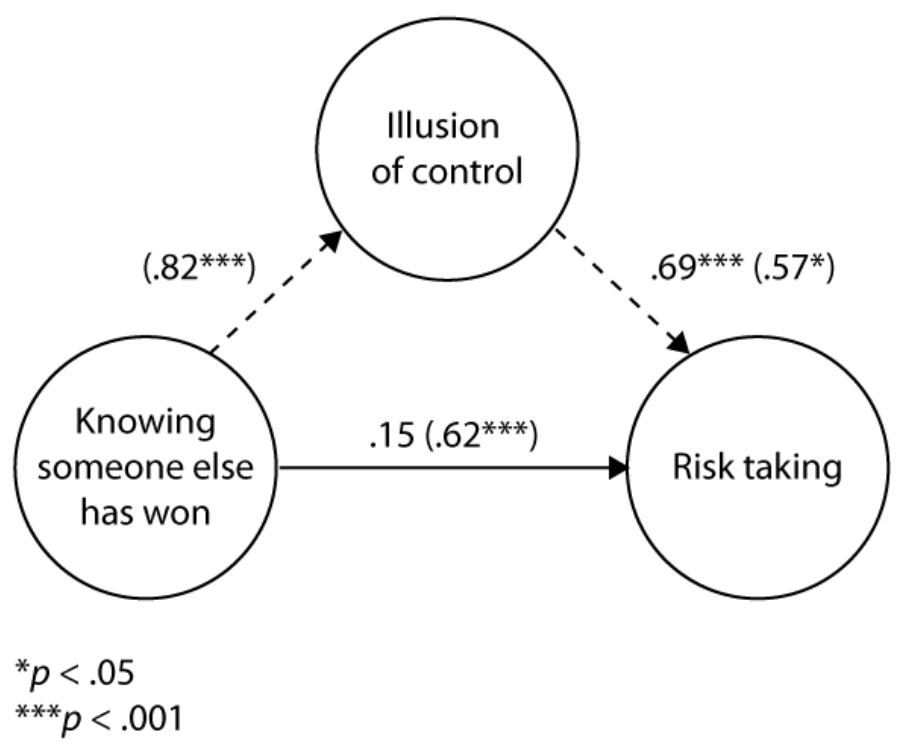


Reports of Wins and Risk Taking 32

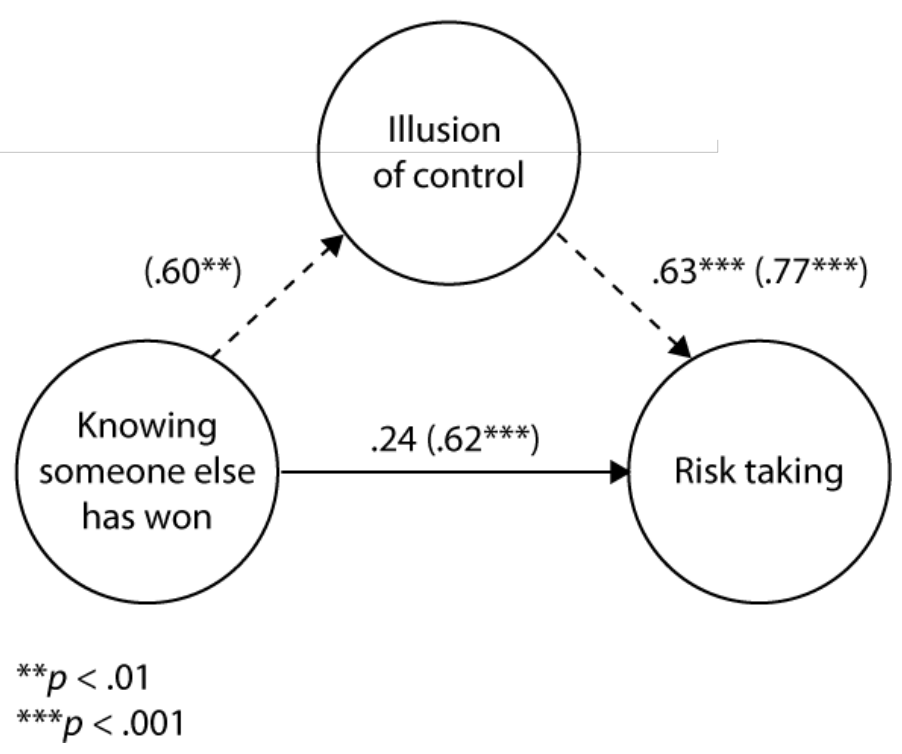

